\title{
FICÇÃO PARA UM CORPO DE CIENTISTA: MARIE CURIE, A INVENÇÃO DE SI E A NARRATIVA AUTOBIOGRÁFICA
}

\author{
PALOMA NASCIMENTO DOS SANTOS
}

Universidade Federal do Rio Grande do Sul

\section{ROCHELE DE QUADROS LOGUERCIO}

Universidade Federal do Rio Grande do Sul

O que nos conta e como se conta uma narrativa de vida nas ciências? E quando quem conta é uma mulher? Marie Curie, física polonesa, criadora do campo da radioatividade e ganhadora de dois prêmios Nobel foi alçada à posição de mito, tendo sua trajetória sido narrada como "exemplo" para as mulheres, nas ciências e fora delas. Curie escreveu, sob encomenda, uma narrativa intitulada Notas autobiográficas, que se encontra como apêndice em um texto também biográfico, escrito pela própria Marie, por ocasião da morte de seu marido. Entendendo que as práticas discursivas das autonarrativas não são autônomas, mas estão incluídas em procedimentos normativos (jurídico, médico, educativo, de gênero) e questionando-se sobre a relação entre as narrativas e as redes de poder articuladas em sua construção, este artigo pretende, a partir das notas autobiográficas de uma mulher considerada um mito, problematizar: (i) as narrativas autobiográficas como invenção de si; (ii) a história de vida de Marie Curie como uma mulher de ciência e a invenção do mito de mãe, esposa e cientista; e (iii) o gênero como elemento central na construção de uma ficção de mulher nas ciências.

Palavras-chave: Marie Curie. Ciência. Autobiografia. Gênero.

\section{ABSTRACT A SCIENTIST BODY FICTION: MARIE CURIE, SELF- INVENTION AND AUTOBIOGRAPHICAL NARRATIVE}

This paper aims to discuss the concept of (i) autobiographical narratives as self-inventing; (ii) the Marie Curie's life story as a woman of science and the invention of the myth of mother, wife and scientist; (iii) and the gender as a central element in the fiction construction of woman in science. Based on the life of this Polish woman, who was physics, creator of radioactivity and winner of two Nobel Prizes, 
this text analyzes Marie Curie as a myth, as she is, so that her trajectory is taken as an example for women inside and outside of the sciences. Curie is the author of a narrative entitled Autobiographical Notes, which is an appendix in a biographical text written by her after her husband's death. The auto-narratives discursive practices are not autonomous. They are included in regulatory procedures (legal, medical, education, gender). Thus, this article intend to discuss the relation between narratives and power networks articulated in this construction.

Keywords: Marie Curie. Science. Autobiography. Gender.

\section{RESUMEN FICCIÓN PARA UN CUERPO CIENTÍFICO: MARIE CURIE, LA INVENCIÓN DE SÍ Y LA NARRACIÓN AUTOBIOGRÁFICA}

Qué nos cuenta y cómo se cuenta una narrativa de vida en las ciencias? Y cuando quien cuenta es una mujer? Marie Curie, física polaca, creadora del campo de la radioatividad y ganadora de dos premios Nobel fue alzada a la posición de mito, su trajetória ha sido narrada como "ejemplo" para las mujeres, en las ciencias y fuera de ellas. Curie escribió una narrativa titulada Notas autobiográficas, que se encuentra como apéndice en un texto tambiém biográfico, escrito por Marie en ocasión de la muerte de su marido. Entendiendo que las prácticas discursivas de las autonarrativas no son autónomas y están incluidas en procedimientos normativos (jurídico, médico, educativo, de gênero), y cuestionandose sobre la relación entre las narrativas y las redes de poder articuladas en su construcción, este artículo pretende problematizar: (i) las narrativas autobiográficas como invención de sí; (ii) la historia de vida de Marie Curie como una mujer de ciencia y la invención del mito de madre, esposa y científica; y (iii) el género como elemento central en la construcción de una ficción de mujer en las ciencia.

Palabras clave: Marie Curie. Ciencia. Autobiografia. Género.

\section{Introdução}

Marie Curie pode ser considerada uma das maiores cientistas que já existiu. Propositora da radioatividade, identificadora dos elementos rádio e polônio, teórica que modificou a concepção da matéria, no século $X X$, multicondecorada em associações científicas e fora delas, criadora do Instituto do Rádio, que deu ao mundo aplicações físicas, químicas e biológicas para o elemento radioativo, e ícone. Mais do que qualquer outra, ela conseguiu transcender sua existência da ciência para se tornar a representação ideal da pesquisadora, 
cientista, mulher e mãe. Sua figura, ao mesmo tempo que aproxima mulheres de sua lenda, hoje, durante o período histórico em que viveu, suscitava discursos inflamados e muito paradoxais. Seus pares dos círculos da ciência, ao mesmo tempo que a transformavam em mártir, por causa da exposição aos materiais radioativos, que culminou na pesquisa sobre a constituição da matéria e no acontecimento da radioatividade, devassavam sua vida pessoal, questionando, dentre outros, o tratamento dado às filhas, e utilizando julgamentos moralizantes para interditá-la das academias e dos círculos científicos. Julie Des Jardins (2011), citando a historiadora Naomi Oreskes, aponta que as convencionais narrativas de heroína ilibada deram errado, quando se trata da construção da persona de Marie Curie. Para este historiador, geralmente seus biógrafos a retratam como "um burro de carga em vez de um Aquiles" (2011, p. 80).

Não nos parece suficiente, hoje, trabalhar a biografia de Marie Curie sem levar em consideração os significativos avanços promovidos pelos estudos de gênero, pois, no momento histórico dessa personagem/mito, as mulheres viviam sob um rígido código moral, cujos efeitos se mostravam fortemente, em diversos impedimentos de participação da vida pública. Não há, no entanto, aqui, nenhuma novidade, pois os estudos feministas e de gênero e ciências, nas últimas décadas, aproximaram Curie de suas problematizações, utilizando sua vida como modelo bifacetado (KOHLSTEDT; LONGINO, 1997; DES JARDINS, 2010; PUGLIESE, 2007; HALL, 2007). Ou sua pessoa é utilizada como exemplo, para discutir relações de trabalho, obstáculos para a ascensão de mulheres nas ciências e crítica à ciência sexista, ou como uma mulher excepcional que bateu de frente e sobreviveu ao mundo androcêntrico das ciências.

O que gostariamos de posicionar em nossa perspectiva é a constituição do mito imerso nas relações de poder e sob os cuidados de estratégias econômicas que raramente são posicionadas nos estudos acadêmicos já realizados sobre a personagem/mito Marie Curie. Como documento a ser analisado, tomamos as pesquisas já empreendidas e as falas que já se realizaram sobre Curie e sua própria narrativa de si. A própria Curie teve a oportunidade de contar-se em um anexo contido na biografia que escreveu do seu marido Pierre Curie, intitulada de Notas autobiográficas, texto que é um retrato que compreende os primeiros anos, a caminhada científica e dá especial atenção aos anos da Primeira Guerra, na França, e as visitas que Curie fez aos Estados Unidos.

Neste texto, nos interessa discutir, utilizando a narrativa autobiográfica, como documento histórico escrito pela própria Marie, as complexidades de ser uma mulher que, ainda em vida, já construía seu legado histórico e cuja autobiografia, durante uma fase bastante produtiva de seu trabalho, poderia trazer beneficios financeiros ou romper o tênue espaço, cunhado no campo das ciências exatas, para o lugar da mulher. Entendendo que as práticas discursivas das autonarrativas não são autônomas, mas estão incluídas em procedimentos normativos (jurídico, médico, educativo, de gênero) e questionando-se sobre a relação entre estas vidas narradas e as redes de poder articuladas em sua construção, este artigo pretende, a partir das notas autobiográficas de uma mulher considerada um mito, problematizar a história de vida de mulheres nas ciências e a invenção dos modelos de mãe, esposa e cientista, e o papel do gênero como elemento central na construção de uma ficção de mulher nas ciências. A "verdadeira" Curie é aquela que se conta? Ou ela se conta utilizando um discurso sitiado que confere caráter de verdade àquilo que é dito?

1 Não há versão em português das Autobiographical notes, todos os textos utilizados nesse artigo são de tradução própria. 


\section{Notas autobiográficas: vida sob encomenda}

Marie escrevia. Toda a família tinha uma produção escrita interessante. Seu pai era um aficionado por literatura e escreveu textos com a história da sua família na Polônia; seu irmão fez uma versão revisada dessa genealogia, acrescentando detalhes da nova geração; sua irmã Helena escreveu memórias em polonês; suas filhas escreveram textos marcantes e a própria Marie escreveu uma biografia de Pierre Curie, seu marido, e uma breve autobiografia. o motivo para que a família Sklodowski e, posteriormente os Curie, se preocupassem tanto com o registro histórico de seus membros era uma perspectiva política. Susan Quinn, autora de uma importante biografia de Marie, acrescenta que:

Como todos os historiadores de família, esses membros do clã Sklodowski-Curie tinham suas razões para fazer esses registros. Para o pai de Marie e, em grande medida, para seu irmão Józef, escrever uma história de família era um ato político, um meio de preservar o precioso legado polonês que opressores estrangeiros tentaram, durante a maior parte de suas vidas, tão brutalmente destruir. Para a irmã de Marie, Helena, e sua filha Irène, o que importava era elaborar um aspecto da história. (QUINN, 1997, p. 11)

Em Notas autobiográficas podemos ler, já desde o princípio, sua posição como escritora e seu objetivo:

Meus amigos americanos me pediram para escrever a história da minha vida. Primeiro, a ideia parecia estranha para mim, mas, persuadida, cedi. De qualquer forma, eu não poderia conceber a minha biografia como uma expressão completa de sentimentos pessoais ou uma descrição detalhada de todos os incidentes que me lembraria. Muitos dos nossos sentimentos mudam com os anos e, quando não desaparecem, podem parecer completamente estranhos; incidentes perdem seu interesse momentâ- neo e podem ser lembrados como se tivessem acontecido com outra pessoa. Mas pode haver na vida alguma direção geral, uma linha contínua, gerada por algumas ideias dominantes e alguns sentimentos fortes, que explicam a própria vida e são característica da personalidade humana. Da minha vida, que não foi fácil como um todo, descrevi o curso geral e os momentos essenciais, e espero que minha história dê uma compreensão da maneira com que vivi e trabaIhei. ${ }^{2}$ (CURIE, 1923, p. 70, tradução nossa)

Introduzindo assim seu texto, Marie Curie justifica o fato de ter feito uma seleção dos momentos de sua vida e duas coisas imediatamente nos chamam a atenção: se os Curie tinham o hábito da escrita, por que Curie estranharia escrever sobre a sua vida? Por que, também, se posiciona marcando a seleção? Certamente uma mulher que a essa altura de sua vida tinha passado por muitos interditos de gênero, sabia o que se pode e o que não se pode dizer, como se pode dizer e sob quais cuidados. A autobiografia exigia, portanto, e talvez daí a estranheza, não que Marie se narrasse, mas que Madame Curie se narrasse. Há uma abissal distância entre uma narrativa pessoal e uma narrativa empresarial, Madame Curie é uma empresa, um laboratório, uma pesquisa, por mais pessoal, mais íntimo e mais cotidiano que pareça para um leitor desatento, sabe-se que o que lá está são narrativas de uma Curie, como a própria autora diz, “[...] muitos

2 I have been asked by my American friends to write the story of my life. At first, the idea seemed alien to me, but I yielded to persuasion. However, I could not conceive my biography as a complete expression of personal feelings or a detailed description of all incidents I would remember. Many of our feelings change with the years, and, when faded away, may seem altogether strange; incidents lose their momentary interest and may be remembered as if they have occurred to some other person. But there may be in a life some general direction, some continuous thread, due to a few dominant ideas and a few strong feelings, that explain the life and are characteristic of a human personality. Of my life, which has not been easy on the whole, I have described the general course and the essential features, and I trust that my story gives an understanding of the state of mind in which I have lived and worked. (CURIE, 1923, p. 70) 
dos nossos sentimentos mudam com os anos e, quando não desaparecem, podem parecer completamente estranhos [...]"3 (CURIE, 1923, p. 70, tradução nossa).

As escolhas, portanto, favoreceram e contribuíram para a construção de uma imagem heróica, mítica, e romântica de seu "esforço" científico. É possível dizer que sua autobiografia constituiu-se em um processo totalmente consciente de invenção de si, mas será que alguma autobiografia seria diferente? A ênfase na construção de uma mulher que sempre teve dificuldades para enfrentar enquanto cientista a fez ganhar a admiração de um outro público, menos capacitado para admirar-se com sua sagacidade acadêmica. Tal como Albert Einstein, Curie se torna midiática, se constrói midiática, diz e faz o possivel dentro desse universo, e, nesse sentido, não constrói sua imagem e tampouco sua autobiografia sozinha. Essa personagem/mito consegue, agora, dialogar com setores e agências de fomento, não exclusivas da ciência, o público, especialmente o norte -americano, que angariou doações de organizações filantrópicas e do governo (FORTUNATI, 2014). A ideia de escrever sobre Pierre e sobre si não partiu de Marie. Sob que condições esse retrato de si foi concebido, já que tinha um objetivo bem definido?

A grande responsável por esse empreendimento foi uma jornalista americana que atendia pelo nome de Marie "Missy" Meloney. O mundo vivia um pós-guerra em que os Estados Unidos, que se uniram tarde ao conflito, foram vistos como salvadores e uma terra de riquezas abundantes. Lá, em 1920, as mulheres da luta sufragista já haviam conquistado o direito ao voto. Missy Meloney era editora de uma das seis maiores revistas femininas do período, a revista The Delineator. Foi ela quem

3 [...] many of our feelings change with the years, and, when faded away, may seem altogether strange [...] (CURIE, 1923, p. 70) organizou uma campanha para arrecadar cem mil dólares para comprar um grama de rádio para Marie Curie e dificilmente essa organização teria unicamente uma vertente acadêmica e científica, para Meloney. Por sua vez, Curie sabia que os Estados Unidos possuíam rádio e, durante um encontro com Missy Meloney, na França, afirmou que "Os Estados Unidos têm cerca de cinquenta gramas de rádio [...] Meu laboratório, respondeu, tem pouco mais de um grama"4 (MELONEY, 1923, p. 12-13) Aqui, podemos encontrar, nos documentos analisados nos textos de Meloney e Curie e também de suas comentadoras -, diversos interesses que se dispersam em setores dispares, mas que mantêm em comum a figura de uma mulher em sua luta por ocupar um espaço que historicamente não foi constituído como seu. Uma campanha massiva, na imprensa, teve início antes mesmo da chegada de Curie aos Estados Unidos, especificamente em Nova Iorque. Meloney movimentava setores acadêmicos e organizações de mulheres americanas e programava encontros e reuniões com autoridades, todas essas pessoas fascinadas com o mito que a influente jornalista estava construindo. A estratégia encontrada para facilitar a aproximação das pessoas americanas com Marie Curie foi escrever a autobiografia já citada. A biografia de Marie Curie não seria importante apenas por seu papel de mulher da ciência, mas porque também o público americano, já com vocação hollywoodiana, exigia conhecer a história de superação de uma vida marcada pela falta de recursos. Segundo Susan Quinn (1997), a ênfase às pobres condições de trabalho dos primeiros anos e a tristeza com o fato de Pierre Curie ter morrido sem conseguir o laboratório de seus sonhos, ambas foram estrategicamente repetidas no texto. Afinal de contas, Marie

4 "America," she said, "has about fifty grammes of radium. [...] "My laboratory," she replied simply, "has hardly more than a gramme". (MELONEY, 1923, p. 12-13) 
era pobre e precisava de dinheiro, ${ }^{5}$ dinheiro da sociedade americana (as condições de possibilidades históricas eram favoráveis para a sustentação desse discurso, pois os Estados Unidos se firmavam como expoente econômico após a Primeira Guerra). Além disso, tanto a autora quanto sua mentora de arrecadações, insistiam na pobreza e na simplicidade como virtudes. Ao relatar, na introdução do livro, o primeiro encontro que teve com Marie Curie, Missy Meloney escreve que "encontrou uma mulher simples, trabalhando em um laboratório inadequado e vivendo em um apartamento modesto, com o salário de uma professora francesa". Acrescenta ainda que "[...] a porta se abriu e vi uma mulher pálida e tímida, com um vestido preto de algodão, com o rosto mais triste que eu já tinha visto [...] seu rosto bonito, belo e paciente, tinha a expressão desligada de uma acadêmica [...]" (MELONEY, 1923, p. 12).

Ainda que estejamos cuidando de entender a autobiografia, essa foi planejada após a encomenda do livro Pierre Curie, pela publicadora francesa Payot, com contrato de publicação assinado em 1 de setembro de 1920, que incluía um livro ao preço de 3 francos, com tiragem de 3.000 exemplares, royalties de $10 \%$ e um valor fixo de 1.000 francos para a autora, a serem pagos em duas parcelas: metade na entrega do manuscrito e a outra metade no momento da publicação. Meloney imediatamente quis saber se Curie estava disposta a publicá-lo nos Estados Unidos. Marie alterou o contrato com a Payot e passou a deter os direi-

5 A pobreza como mito, comum em narrativas hagiográficas, está presente no processo de invenção de si de Curie. Susan Quinn afirma que a insistência em pintar uma cientista pobre, e sobretudo francesa, causou ressentimentos. O que Missy Meloney contava era uma França atingida, por anos, pela Guerra, uma ficção sentimental de uma mulher que produzia ciência em um canto do mundo devastado. Em contrapartida, Marie tinha uma situação mais próspera que muitos cientistas à época: possuía seu próprio laboratório construído a partir de suas especificações, recebia a cada dia mais doações e tinha seu salário suplementado por uma pensão dada pelo governo francês. (QUINN, 1997) tos de tradução, cedendo apenas a publicação francesa, pois a ideia seria internacionalizar o texto, ao traduzi-lo para o inglês. Ao receber o Notas autobiográficas, Missy Meloney preocupou-se com o fato dele ser muito pequeno, e não "muito pessoal", para o público americano, persuadindo Marie Curie a publicá-las em conjunto, no livro Pierre Curie. Segundo Eva Wirtén (2015), Marie sabia que as pessoas leitoras estavam tão interessadas nela quanto em seu marido, se não mais.

A produção do livro foi recheada de problemas, com Missy Meloney tendo que implorar para que Curie entregasse um manuscrito para realizar provas da tradução, pois Marie estava receosa de ter problemas com a Universidade de Paris, por causa da introdução escrita por Meloney, além do fato de que se encontrava muito ocupada com a celebração em Paris do vigésimo quinto aniversário da descoberta do rádio (WIRTÉN, 2015). Mais uma vez podemos identificar que a produção de uma autobiografia não é o simples narrar de uma história que contamos de nós mesmas, é trabalhar com estratégias de pertencimento a esta ou aquela instituição, a este ou aquele contrato, a esta ou aquela forma de contar a história, no caso de Marie, soma-se a não aposentadoria: não é uma memória do passado, é uma memória do futuro.

As Notas autobiográficas aparecem, então, como anexo na edição americana da biografia Pierre Curie, e são um conjunto de quatro capítulos. O primeiro compreende os anos da infância, o trabalho pré Paris, a vida na França e o casamento. Trata-se de uma narrativa saudosa dos tempos da infância e da adolescência passados na Polônia e da afirmação de um grande esforço pessoal para conseguir estudar em uma das melhores universidades do mundo. No segundo capítulo, Marie alterna uma narrativa sobre sua vida, como mãe e esposa, com o trabalho de pesquisa que culminou no aconte- 
cimento da radioatividade. É nesse momento da autobiografia que ela pontua mais especificamente as perspectivas sobre o casamento, a morte de Pierre, o cuidado com as filhas e seu relacionamento com a ciência. 0 terceiro capítulo é dedicado aos anos da guerra e seu serviço aplicado nos fronts, com a "curieterapia" e, a última parte das notas, relata a visita que fez aos Estados Unidos, com destaque para os encontros que teve com autoridades políticas e acadêmicas, ressaltando, em tons excessivamente agradecidos, a generosidade das pessoas americanas, suas doadoras. Como bem podemos relembrar, Marie Curie fala do lugar institucional que é o da pesquisadora, convenientemente desaparecem nestas notas tudo o que polemizaria ainda mais sua vida: amores, desafetos, desrespeito e sua possibilidade como mulher cientista. Marie, em quase todas as linhas do seu texto, não "milita" nas arenas sociais vigentes, não se posiciona politicamente, não age como uma intelectual. Marie, em sua notas autobiográficas, é a cientista mulher, Marie é Curie.

\section{Marie Curie e a narrativa autobiográfica}

A biografia é um tipo de narrativa que se ocupa da vida. Situada entre a história e a ficção, encontra resistência quando se torna objeto de estudo ou quando é utilizada como fonte. Para Gobbi (2005), definir o que seria uma biografia é tarefa impossível, pois se trata da tentativa de enquadrar um construto "deslizante" (COSTA, 2010), que abrange a literatura, a história, a sociologia, a filosofia, a antropologia, a educação. Além do seu caráter híbrido e interdisciplinar, a biografia dissolve a autora ou o autor. Para Dominique Viart (2002), a biografia deve ser expandida para além do gênero literário para que - o autor substitui pelo termo biográfico - o biográfico se torne o efeito do vivido, abando- nando qualquer expectativa em relação a uma realidade histórica dos fatos. A biografia é “prática vivida, gesto pragmático da vida cotidiana sem ambição literária" (VIART, 2002, p. 65). Mais além, o biográfico fabula, inventa formas e corpos, articulando ficção e pensamento crítico, "a invenção de si como se fora um outro" (VIART, 2002, p. 73), deslizando, assim, entre história e ficção. Se tomarmos as biografias ou escritos biográficos que também encontram porto nas trajetórias científicas, como documentos de análise e da mesma forma que Dominique Viart (2002), lhes outorgarmos a construção do fato como inerente, podemos assumir a ficção em sua potência de verdade. Multiplicam-se os livros biográficos dos - masculino - notáveis nas ciências, pois Galileu, Darwin, Pasteur tiveram seus feitos ficcionalizados, suas vidas inventadas e seus corpos construídos em centenas de livros da categoria. Entre muitos nomes, destaca-se o de Marie Curie como aquela que representa o interesse das publicações para além, ou talvez por causa disso, de ser uma mulher nas ciências.

Neste texto, se utiliza um tipo de narrativa de vida, a autobiografia. Como estratégia metodológica, então, se considera importante o uso de narrativas de história de vida, como autobiografias ou romances autobiográficos, enquanto objeto de pesquisa prevendo três aspectos importantes a ser observados antes, no procedimento analítico: admitir que a realidade é uma construção, entender que a identidade é um estado em processo e compreender que todo o conhecimento será sempre uma construção de fatos com efeito de verdade. Assim sendo, utilizar depoimentos, documentos ou biografias de alguém sobre si mesmo deve se pautar pelo objetivo de não empreender por uma busca de algo verdadeiro (em nosso caso, uma Marie Curie real, confrontada com uma Marie Curie fictícia, contida em seu próprio texto), mas a identificação das condições 
de possibilidade para que determinada narrativa emerja enquanto discurso (FISCHER, 2004). Entende-se que com as palavras se faz, se cria, se inventa até mesmo a si. Inventar-se a si, no sentido de não ser só apenas um objeto no discurso, das práticas e das estratégias do poder, mas variar-se em relação a si mesma, ficcionar a si, (re)inventando-se a partir da negação da essencialidade (REVEL, 2006). Outra preocupação no percurso é considerar as condições de possibilidade para que estes discursos do sujeito Marie Curie, que se narra, emerjam. Isso é possivel a partir do olhar para o contexto histórico, contudo, sem considerar que aquela mulher que se narra é uma mulher essencial, um retrato único e estático de cientista, mãe, mulher, esposa.

É preciso, também, associar a análise à compreensão da dinâmica das relações de poder e, neste trabalho, observar como o gênero opera dentro e fora delas. 0 gênero é aqui entendido como ponto de vista e conceito central para a análise, pois a construção da figura de mulher, empreendida pela própria Marie e pela polifonia que a ajudou a escrever, é marcada por interditos, negociações e pela construção de uma imagem de "mulher ideal" nas ciências, estudada e criticada por pesquisadoras da área de gênero e ciências (KELLER, 1982; 1995; 2001; 2006; SCHIEBINGER, 2001). A partir dessas estratégias, segue-se então em uma perspectiva de fazer falar, através da autobiografia de Marie, as diferentes identidades que Curie nos narra agora: estudante, esposa, mãe e cientista.

\section{A estudante incansável}

Os anos de estudo de Marie receberam especial atenção no texto, reafirmando a educação que recebeu e que foram fruto da preocupação primordial de seu pai e da sua mãe, com os estudos das filhas e filhos. Marie relata que pretendia seguir estudando, e, sobre suas escolhas, confessa o encontro com as ciências:
“[...] durante estes anos de trabalho isolado, tentando pouco a pouco definir minhas preferências verdadeiras, finalmente escolhi matemática e física, e me comprometi resolutamente a me preparar seriamente para os futuros exames [...]"6 (CURIE, 1923, p. 74).

Marie desejava estudar fora da Polônia, e sobre o período de vida que se seguiu, depois de terminar os estudos básicos, ela escreve:

Meu estudo solitário foi cheio de dificuldades. A educação científica, que eu tinha recebido no liceu era muito incompleta; era muito abaixo do nivel do programa de bacharelado de um liceu francês; eu tentei complementar meus estudos do meu jeito, com a ajuda de livros, pegos aleatoriamente. Este método não foi extremamente produtivo, mas ainda não foi sem resultados. Eu adquiri o hábito de estudar de forma independente e aprendi algumas coisas que usaria mais tarde. Tive de modificar meus planos para o futuro, quando minha irmã mais velha decidiu ir para Paris estudar medicina. Tínhamos prometido nos ajudar mutuamente, mas nossos meios não permitiam que fôssemos juntas. Então eu mantive meu emprego por três anos e meio e, tendo terminado o meu trabalho com meus alunos, eu retornei para Varsóvia, onde uma vida, semelhante àquela da qual tinha saído, estava me esperando.? (CURIE, 1923, p. 74, tradução nossa)

Ainda sobre as tentativas de complementar seus estudos visando se preparar para os

6 [...] during these years of isolated work, trying little by little to find my real preferences, I finally turned towards mathematics and physics, and resolutely undertook a serious preparation for future work [...] (CURIE, 1923, p. 74)

7 My solitary study was beset with difficulties. The scientific education I had received at the lyceum was very incomplete; it was well under the bachelorship program of a French lyceum; I tried to add to it in my own way, with the help of books picked up at random. This method could not be greatly productive, yet it was not without results. I acquired the habit of independent work, and learned a few things which were to be of use later on. I had to modify my plans for the future when my eldest sister decided to go to Paris to study medicine. We had promised each other mutual aid, but our means did not permit of our leaving together. So I kept my position for three and a half years, and, having finished my work with my pupils, I returned to Warsaw, where a position, similar to the one I had left, was awaiting me. (CURIE, 1923, p. 74) 
exames franceses, Marie mostrava insistência ao narrar que frequentava o laboratório municipal de fisica, à noite e aos domingos. Sobre suas estratégias no campo experimental, Curie disserta:

Eu tentei fazer várias experiências descritas nos tratados de física e química e os resultados eram por vezes inesperados. Às vezes, eu era incentivada por um pequeno sucesso simples, em outros momentos, ficava no mais profundo desespero por causa de acidentes e falhas resultantes da minha inexperiência. Mas, no geral, embora eu soubesse que o caminho do progresso não é rápido nem fácil, esta primeira experiência confirmou em mim o gosto pela pesquisa experimental nos domínios da física e da química. ${ }^{8}$ (CURIE, 1923, p. 74, tradução nossa)

Os métodos encontrados para suprir as deficiências de seu ensino básico incluíam organizar sozinha um plano de estudos e se preparar absurdamente. Além das lacunas existentes em sua formação básica, se quisesse estudar mais do que era permitido às mulheres, na época, ou estudar em Paris, Marie tinha que se preparar, especialmente por ser mulher. Eulalia Pérez Sedeño (2004) denominou essa estratégia de sobrevivência de "estratégia Mme. Curie". Para conseguir trânsito e aceitação em uma atmosfera hostil e competitiva - masculina -, as mulheres tinham que estar "melhor e excessivamente preparadas, ser modestas, disciplinadas e estóicas, infinitamente estóicas", pois desejavam conquistar "bastiões nos trabalhos dos homens" (SEDEÑO, 2004, p. 210). A estudante Marie, narrada pela pesquisadora Curie, é uma lutadora, não tem tempo para outra coisa que não seus estudos, sua "desvanta-

8 I tried out various experiments described in treatises on physics and chemistry, and the results were sometimes unexpected. At times I would be encouraged by a little unhoped-for success, at others I would be in the deepest despair because of accidents and failures resulting from my inexperience. But on the whole, though I was taught that the way of progress is neither swift nor easy, this first trial confirmed in me the taste for experimental research in the fields of physics and chemistry. (CURIE, 1923, p. 74) gem", sua perda, suas lacunas em relação aos estudos formais e a outros estudantes do sexo masculino. Narrar esse aspecto adolescente da vida de Marie, a que estuda, serve a uma parcela das leitoras das Notas autobiográficas, jovens estudantes, mulheres matriculadas nos women's colleges espalhados pelos Estados Unidos. Estas faculdades femininas ofereciam o bacharelado para mulheres e poucos ofereciam cursos de mestrado.

Novamente tratando sobre de sua organização cotidiana para driblar as dificuldades, Marie escreve que os primeiros anos em Paris foram dificeis, mas as dificuldades pareciam ser um padrão para estudantes estrangeiros, em sua época. Ela narra que "A minha situação não era excepcional; era muito semelhante à de muitos estudantes polacos que conhecia" ${ }^{\prime}$ (CURIE, 1923, p. 75, tradução nossa). É interessante perceber que os estudantes polacos são enfatizados no texto, certamente, essa era a realidade de muitos estudantes de várias etnias, inclusive a francesa, porém Marie marca seu pertencimento à Polônia. Conta também sobre o local onde vivia, pois, ao chegar na França, ficou hospedada na casa da sua irmã Bronia, mas logo alugou um quarto mais próximo da universidade. Apesar do conforto de morar com a irmã e o cunhado, o apartamento raramente estava silencioso, pois recebia visitas de pacientes do casal e de pessoas polonesas conhecidas (QUINN, 1997). Marie referia-se ao tempo em que passou morando sozinha como um período de muita liberdade em um cotidiano "[...] de uma calma e grande satisfação moral [...]"10 (CURIE, 1923, p. 76, tradução nossa). Uma vez mais, Marie diz o que pode dizer, o que se espera como explicação para deixar o conforto e a segurança da casa

9 However, my situation was not exceptional; it was the familiar experience of many of the Polish students whom I knew. (CURIE, 1923, p. 75)

10 [...] if sometimes I felt lonesome, my usual state of mind was one of calm and great moral satisfaction [...] (CURIE, 1923, p. 76) 
da irmã que ela ajudou a se formar. Nesse momento, nos Estados Unidos, como em tantos outros países, as mulheres precisam explicar suas escolhas, confessar-se. Marie se confessa, e admite que, apesar de tudo, não era fácil viver com essa escolha. Sobre isso ela escreve:

o quarto onde eu morava ficava num sótão, muito frio no inverno, por isso o aquecimento era feito por um fogão pequeno e muitas vezes faltava carvão. Durante um inverno particularmente rigoroso, onde não era incomum a água da bacia congelar à noite; para poder dormir, fui obrigada a juntar todas as minhas roupas como um cobertor. [Eu dormia] Na mesma sala onde preparava minhas refeições, com o auxílio de uma lâmpada de álcool e alguns utensílios de cozinha. Estas refeições muitas vezes eram um pão com uma xícara de chocolate quente, ovos ou frutas. Eu não tinha nenhuma ajuda com as tarefas domésticas, e carregava o pouco carvão que utilizava subindo seis andares.11 (CURIE, 1923, p. 76, tradução nossa)

Mesmo vivendo em um lugar tão pobre, escrever sobre essa sensação de liberdade era algo revolucionário para uma mulher, na $\mathrm{Pa}$ ris do século XIX. Para Susan Quinn (1997), tal autonomia era uma realização rara para uma mulher, especialmente em uma cidade onde as jovens francesas bem comportadas não ousavam sair de casa desacompanhadas. Marie, porém, fabula a autora, voltava para casa tarde da noite, vindo da biblioteca, sozinha, por ruas estreitas, seguindo para o seu quarto de solteira. O processo de se narrar como estudante esforçada é próprio de uma época em que as marcas do biológico e seus discursos dispersos eram um dos interditos que as mulheres teriam que enfrentar, se quisessem es-

11 During a particularly rigorous winter, it was not unusual for the water to freeze in the basin in the night; to be able to sleep I was obliged to pile all my clothes on the bedcovers. In the same room I prepared my meals with the aid of an alcohol lamp and a few kitchen utensils. These meals were often reduced to bread with a cup of chocolate, eggs or fruit. I had no help in housekeeping and I myself carried the little coal I used up the six flights. (CURIE, 1923, p. 76) tudar mais do que lhes era devido. Lucía Tosi (1998) afirma que durante muitos séculos as atividades intelectuais foram desaconselhadas para as mulheres, pois contrariavam seu destino biológico. A autora cita médicos como George Cabanis (1757-1808), que insistia em mostrar que a fisiologia feminina condiciona o organismo das mulheres para desempenhar seu papel precípuo de mãe e esposa. As moças das classes mais ricas recebiam um pouco mais de instrução e poderiam aprender música, canto e dança - artes, essa coisa feminina.

Marie Curie escreve sobre ter sido muito pobre, no entanto, é interessante perceber que ela teve uma infância de incentivo aos estudos, mãe e pai intelectuais e cresceu em uma casa repleta de livros e produção cultural, um perfil que não era um padrão para as moças da época, muito menos para as moças pobres da época. Curie conhecia o que era viver com poucos recursos, pois, apesar da preocupação intelectual, era uma das filhas de uma família numerosa, que na infância sofreu com a morte da mãe, e que viu seu pai conseguir recursos financeiros ao transformar sua casa em um internato para meninos, privando as filhas de privacidade. Marie escapou desses interditos e, como desejava a carreira científica, e vivia em um contexto histórico de plena formalização da ciência, ela teria dois caminhos a seguir: ou estudar bastante para ingressar em alguma universidade, ou, por meio da família (formação na esfera privada), pesquisar como assistente de um marido, pais ou irmãos (SCHWARTZ et al, 2006; TOSI, 1998). Sua escolha incluiu a primeira opção, e em sua autobiografia reforça o seu caráter de heroína, ao afirmar que:

Meu cunhado, recordando mais tarde estes anos de trabalho sob as condições que eu acabei de descrever, ironicamente se referia a eles como "o período heróico da minha cunhada". Sempre considerarei dentre as melhores lem- 
branças da minha vida esse período de anos solitários, exclusivamente dedicados aos estudos, finalmente, ao meu alcance, pelos quais eu tinha esperado tanto tempo.12 (CURIE, 1923, p. 76-77, tradução nossa)

Graduou-se em Física e Matemática, em primeiro e segundo lugar, respectivamente. A excepcionalidade e a genialidade é uma das características mais celebradas de Curie e costuma ser associada à sua figura, imprimindo uma essencialidade. É possivel para Marie ser essencialmente um gênio e ao mesmo tempo estóica e altamente esforçada? Não parece fazer muito sentido. Marie pretendia, desde muito jovem, ser cientista e, para isso, teria que adentrar em um reduto masculino. Era esse reduto, por meio do exercício do poder, na multiplicidade de suas relações, que definia como as mulheres deveriam agir. 0 gênero aparece, então, como determinante para marcar essa estratégia do esforço, pois muitas mulheres, no decorrer da história, se esforçaram herculeamente e continuaram invisiveis (PUGLIESE, 2007).

\section{Um casamento científico}

As mulheres, num processo cultural de dominação masculina, foram sistematicamente subjugadas aos seus pais ou maridos. Os relacionamentos afetivos para as mulheres eram, e ainda são, em alguns casos, lugares de mudança de status quo. Na vida de Marie Curie, isso aconteceu duas vezes: quando se casou com Pierre Curie e quando se tornou viúva. Esses dois momentos são marcantes, mas particularmente na vida de Marie e nas Notas autobiográficas, o casamento ganha um destaque, foi um casamento científico e sua histó-

\footnotetext{
12 My brother-in-law, recalling later these years of work under the conditions I have just described, jokingly referred to them as "the heroic period of my sister in -law's life". For myself, I shall always consider one of the best memories of my life that period of solitary years exclusively devoted to the studies, finally within my reach, for which I had waited so long. (CURIE, 1923, p. 76-77)
}

ria vinha ao encontro da história das mulheres americanas.

A estrutura de arrecadação de fundos para financiar o grama de rádio para Marie Curie era composta por uma comissão consultiva masculina, formada por pesquisadores do câncer e técnicos, e uma comissão feminina, liderada pela fundadora da American Society for the Control of Cancer. Mas, apesar das duas frentes formadas, o montante de doações, sejam grandes ou pequenas, veio das mulheres (GOLDSMITH, 2006). As estadunidenses tinham adquirido o direito ao voto, no ano anterior à organização da campanha para Curie, e começaram a impor sua igualdade. Marie Curie seria apresentada a elas, em sua autobiografia, como uma mulher que, além de se dedicar à ciência, era alguém para quem o casamento era uma possibilidade.

Aquela estudante reclusa do sótão agora tinha um companheiro, pesquisador e apaixonado pela ciência como ela. Curie demonstra essa prerrogativa, ao escrever: "Meu marido e eu éramos tão intimamente unidos por nosso afeto e o nosso trabalho em comum que passamos quase todo o nosso tempo juntos"13 (CURIE, 1923, p. 79, tradução nossa). Barbara Goldsmith (2006) também destaca esse perfil de casamento científico, ao apontar que Marie trouxe para o casamento o mesmo entusiasmo que tinha pela ciência. Ela estudava sobre os afazeres domésticos como se fossem propostas científicas e chegava a calcular estatisticamente os rendimentos de suas receitas. Sobre a rotina cotidiana, ela escreve:

Como nossos recursos materiais eram limitados, fui obrigada a assumir a maior parte da limpeza, e particularmente a preparação de refeições. Não foi fácil conciliar essas tarefas domésticas com meu trabalho científico, ainda que, com boa vontade, eu consegui. A coisa

13 My husband and I were so closely united by our affection and our common work that we passed nearly all of our time together. (CURIE, 1923, p. 79) 
mais importante era que estávamos sozinhos e juntos naquela pequena casa que nos deu uma paz e uma intimidade que eram muito agradáveis para nós.14 (CURIE, 1923, p. 79, tradução nossa)

Pierre tinha uma plataforma de pesquisa que foi completamente abandonada para que ele se juntasse às problematizações de Marie, que estava ocupada em investigar o fenômeno das emanações, a partir da análise dos minérios e da suspeita de que poderia se tratar de uma propriedade atômica e de um elemento novo. Pierre se juntou à esposa e o trabalho passou a ser do casal Curie. Marie teria sua história intrinsecamente ligada à vida do seu marido, 15 inserindo ao seu perfil mitológico a faceta da esposa abnegada. Ao analisar o uso das palavras na autobiografia, Julie Des Jardin (2011) afirma que é importante estar atento ao modo como Marie Curie usa o "eu" e o "nós", e justifica isso, ao perceber que Marie, ora se mostrava assertiva, utilizando a primeira pessoa, ora dividia os achados de pesquisa com o marido. Para a autora, Curie usou muito conscientemente a biografia de seu marido e a própria para articular seu papel no que diz respeito à ciência da radioatividade e à discussão em relação à apropriação do rádio (DES JARDINS, 2011). o que significa não ser um "eu" nas ciên-

14 As our material resources were limited, I was obliged to attend to most of the housekeeping myself, particularly the preparation of meals. It was not easy to reconcile these household duties with my scientific work, yet, with good will, I managed it. The great thing was that we were alone together in the little home which gave us a peace and intimacy that were very enjoyable for us. (CURIE, 1923, p. 79)

15 Sobre relações conjugais nas ciências, Betina Lima (2008) cria o conceito de "efeito Camille Claudel", escultora francesa que teve sua carreira impulsionada e obscurecida, ao mesmo tempo, por Rodin, que era seu amante. Após iniciar o romance com Rodin, Camille adequa as escolhas artísticas às dele e ambos iniciam uma relação de concorrência, danosa para ela, que acaba doente e tendo seu talento desvalorizado. Betina Lima utiliza essa relação como ilustração para debater que o gênero, operado pelas relações de poder e nas relações de trabalho, pode ser um ponto determinante para o efeito Camille Claudel (carreiras encaixadas, ofuscamento da mulher por causa do gênero, relação de concorrência). cias? O pronome "nós" excluía as mulheres, pois, como sua representação nas ciências era pouca, ser aglutinada em uma narrativa era ficar invisivel e ter seus trabalhos esquecidos na história, ou atribuído aos homens. Mas, ao mesmo tempo que invisibilizava, naquela época em que as mulheres não eram bem recebidas pelos círculos científicos, ser um casal permitia a Marie publicar, ser lida, alavancar sua carreira e ter suas problematizações levadas a sério (PUGLIESI, 2007).

A divisão de trabalho do casal Curie estava inserida dentro do binário masculino/feminino, objetividade/subjetividade, razão/emoção, discurso disperso na época. Sobre seu trabalho, Curie escreve que:

Muitas vezes, eu tinha que preparar nosso almoço no galpão, para não interromper uma operação particularmente importante. Às vezes, eu tinha que passar um dia inteiro com uma haste de ferro pesada, quase do meu tamanho, mexendo uma massa fervente de mistura. Ao fim do dia, eu estava arrasada e com fadiga. Outros dias, pelo contrário, o trabalho seria uma cristalização fracionada, mais minuciosa e delicada, no esforço de concentrar-se no rádio. ${ }^{16}$ (CURIE, 1923, p. 83, tradução nossa)

Apesar de ser uma parceria, o trabalho do casal seguia com Marie preparando amostras e purificando sais, a partir dos minérios, numa sequência analítica exaustiva, durante anos, enquanto Pierre recebia os sais puros e refletia sobre a origem da energia radioativa, com o papel de pensador dos eventos. A divisão dual marcada pelo gênero estava exposta no trabalho científico do casal. Marie era colocada na posição de assistente do marido (que era quem tinha o emprego com visibilidade,

16 Often I had to prepare our lunch in the shed, so as not to interrupt some particularly important operation. Sometimes I had to spend a whole day mixing a boiling mass with a heavy iron rod nearly as large as myself. I would be broken with fatigue at the day's end. Other days, on the contrary, the work would be a most minute and delicate fractional crystallization, in the effort to concentrate the radium. (CURIE, 1923, p. 83) 
professor da escola de engenharia e, portanto, alguém a ser ouvido), e se narrar assim reverbera uma teia de discursos que reforçava a imagem de inaptidão das mulheres para o trabalho reflexivo, ou racional - o que, em parte, legitimava o exercício do poder distribuído - e colocava Marie Curie na posição de auxiliadora. Marie descreve o exaustivo trabalho que realizava, porém afirma que encontrava prazer em meio a tanto cansaço. Demonstrava a força com a qual foi alçada à posição de mito, ao narrar que:

O sentimento de desânimo que às vezes vinha, após alguns experimentos malsucedidos, não durava muito e dava lugar a uma atividade renovada. Tínhamos momentos felizes, dedicados a discutir a tranquilidade de nosso trabalho, enquanto caminhávamos em nosso galpão. Uma das nossas alegrias foi entrar em nossa sala de trabalho, durante a noite, e percebermos, por todos os lados, as silhuetas debilmente luminosas das garrafas e cápsulas, contendo nossos produtos. Foi realmente uma vista linda e sempre nova para nós. Os tubos de incandescência pareciam delicadas luzes, como fadas luminosas.17 (CURIE, 1923, p. 83, tradução nossa)

Em se tratando de trabalhos realizados por casais nas ciências, Londa Schiebinger (2001) demonstra que a história da ciência se interessou pelo estudo da colaboração entre maridos e mulheres e como, especialmente para as mulheres, o casamento serviu de caminho informal para a ciência. Além da oportunidade de ter um trabalho ao lado do marido e receber mais instrução do que aquela que the era oferecida, as mulheres, por causa da centralidade do masculino nas ciências,

17 The feeling of discouragement that sometimes came after some unsuccessful toil did not last long and gave way to renewed activity. We had happy moments devoted to a quiet discussion of our work, walking around our shed. One of our joys was to go into our workroom at night; we then perceived on all sides the feebly luminous silhouettes of the bottles or capsules containing our products. It was really a lovely sight and one always new to us. The glowing tubes looked like faint, fairy lights. (CURIE, 1923, p. 83) acabavam realizando trabalhos ditos femininos. Esses trabalhos eram essencialmente técnicos, repetitivos, altamente detalhados, porém maçantes. A reflexão era do homem e o quebrar pedras de pechblenda era da mulher (SCHIEBINGER, 2001).

Seu casamento passou também por mais uma virada excepcional: Marie Curie ficou viúva muito cedo. Seu marido faleceu tragicamente, e durante o período de mais intensa produção da radioatividade na França. Sobre esse fato, Marie nos conta que sofreu muito, pois a tragédia "[...] levou o meu marido para longe de mim e me deixou sozinha para cuidar das nossas filhas e, ao mesmo tempo, para continuar nosso trabalho de pesquisa [...]"18 (CURIE, 1923, p. 87, tradução nossa). Com a morte de Pierre, Marie assume a liderança do grupo de pesquisa e também passa a substituí-lo nos espaços em que ser mulher era impensável. Ela, em sua biografia, não admite a entrada na Sorbonne, como uma oportunidade advinda de seu trabalho, que revolucionou a ciência da época, mas como um presente:

Foi em grande parte, sob a influência desta emoção, que a faculdade de Ciências de Paris decidiu oferecer-me a cadeira, como professora, que meu marido tinha ocupado, há apenas um ano e meio, na Sorbonne. Foi uma decisão excepcional, porque até então nenhuma muIher tinha ocupado aquela posição. A Universidade, fazendo isso, demonstrou sua preciosa estima e me deu a oportunidade de prosseguir nas pesquisas que, de outra forma, talvez teriam de ser abandonadas. Eu não esperava um presente desse tipo; eu nunca tive qualquer outra ambição do que ser capaz de trabalhar livremente para a ciência. A honra que me viria agora era profundamente dolorosa sob as cruéis circunstâncias da sua vinda. Além disso, eu me perguntei se eu seria capaz de enfrentar uma tão grande responsabilidade. Depois de muita hesitação, eu decidi que deveria ao menos tentar conhecer o trabalho, e então eu comecei em

18 [...] which took my husband away from me and left me alone to bring up our children and, at the same time, to continue our work of research [...] (CURIE, 1923, p. 87) 
1906 minhas aulas na Sorbonne, como professora-assistente, e dois anos mais tarde, eu fui nomeada professora titular. ${ }^{19}$ (CURIE, 1923, p. 87, tradução nossa)

Goldsmith (2006) e Quinn (1997), salientam que apenas a morte de Pierre alterou o status profissional de Marie Curie. A figura da triste viúva, com seu eterno vestido de algodão preto, atraía condolências ao mesmo tempo em que promovia oportunidades para a cientista. Ela agora deixava de ser a companheira de pesquisa e honras e passava a ser uma profissional independente. Em um período ainda contaminado por distinções de gênero, a mudança no estado civil de Curie, de esposa para viúva, assim, forçava ajustes não só em sua família, mas também em sua vida profissional, na Sorbonne e dentro do círculo interno de pesquisa sobre radioatividade (FORTUNATI, 2014). É nítido o poder que circula entre as relações. Antes cientista genial, porém sem espaço de fala e atuação, por ser mulher, mas ainda assim acompanhada. Agora viúva, a substituição se dá por ser a pessoa que deve garantir o legado do marido, afinal de contas, se não a colocarmos como protagonista, a pesquisa sobre radioatividade arrefece. Mas ela é uma mulher. Mais uma vez, Marie Curie se apresenta como um corpo que escapa.

19 It was largely under the influence of this emotion that the Faculty of Sciences of Paris decided to offer me the chair, as professor, which my husband had occupied only one year and a half in the Sorbonne. It was an exceptional decision, as up to then no woman had held such a position. The University by doing this offered me a precious mark of esteem and gave me opportunity to pursue the researches which otherwise might have had to be abandoned. I had not expected a gift of this kind; I never had any other ambition than to be able to work freely for science. The honor that now came to me was deeply painful under the cruel circumstances of its coming. Besides I wondered whether I would be able to face such a grave responsibility. After much hesitation, I decided that I ought at least to try to meet the task, and so I began in 1906 my teaching in the Sorbonne, as assistant professor, and two years later I was named titular professor. (CURIE, 1923, p. 87)

\section{Maternidade}

Sobre ser mãe, Marie escreve que “[...] o nascimento de nossa primeira filha trouxe uma grande mudança em nossa vida [...]"20 (CURIE, 1923, p. 80, tradução nossa) e escreve sobre a dificuldade que enfrentava para conciliar as tarefas do privado e da pesquisa científica:

Cuidar da nossa casa e da nossa pequena Irene, sem desistir do meu trabalho científico, tornou-se um problema sério. Tal renúncia teria sido muito dolorosa para mim, e meu marido não iria sequer pensar nisso; ele costumava dizer que tinha uma esposa justamente para compartilhar todas as suas preocupações. $\mathrm{Ne}$ nhum de nós queria abandonar o que era tão precioso para ambos. Claro que tínhamos de ter uma empregada, mas eu pessoalmente cuidava de todos os detalhes do cuidado da criança. Enquanto eu estava no laboratório, ela estava sob os cuidados de seu avô, que a amava ternamente e cuja própria vida teve mais sentido por ela. Então, esse suporte da nossa família foi o que me permitiu cumprir minhas obrigações. As coisas eram particularmente dificeis apenas durante eventos mais excepcionais, como, por exemplo, quando a criança ficava doente e quando noites sem dormir interrompiam o curso normal da vida. ${ }^{21}$ (CURIE, 1923, p. 80, tradução nossa)

Curie era mãe e estava inscrita em um momento histórico que imprimia e cobrava das mulheres o desejo e a devoção à maternida-

20 [...] the birth of our first daughter brought a great change in our life [...] (CURIE, 1923, p. 80)

21 It became a serious problem how to take care of our little Irene and of our home without giving up my scientific work. Such a renunciation would have been very painful to me, and my husband would not even think of it; he used to say that he had got a wife made expressly for him to share all his preoccupations. Neither of us would contemplate abandoning what was so precious to both. Of course we had to have a servant, but I personally saw to all the details of the child's care. While I was in the laboratory, she was in the care of her grandfather, who loved her tenderly and whose own life was made brighter by her. So the close union of our family enabled me to meet my obligations. Things were particularly difficult only in case of more exceptional events, such as a child's illness, when sleepless nights interrupted the normal course of life. (CURIE, 1923, p. 80) 
de. Essa construção se apoia sobretudo no discurso médico e biológico, que confere uma vocação natural da mulher para o cuidado maternal. Estes enunciados se movimentavam numa composição de discursos de escrutínio do corpo feminino. As diferenças marcantes eram apontadas para comprovar a tendência natural da mulher para gerar filhas e filhos. Se a ideia circulante, principalmente nos séculos XVII e XVIII, era que a essência se define por funções orgânicas, as mulheres com suas bacias alongadas e mamas selavam, no corpo, o destino de ser mãe (ROHDEN, 2003; SCHIEBINGER, 1987). Curie narra o processo de ser mãe que vive e também relata sobre esse cuidado de si e do outro, ou das outras, suas filhas. Em seu texto, escreve:

Mas claro, o cuidado da educação das minhas filhas era apenas uma parte dos meus deveres, em que minhas ocupações profissionais levavam a maior parte do meu tempo. Eu era frequentemente questionada, especialmente por mulheres, como poderia conciliar a vida familiar com uma carreira científica. Bem, isso não foi fácil; requer uma grande quantidade de decisão e de autossacrifício. No entanto, o vínculo familiar foi preservado entre mim e minhas filhas, agora adultas, e a vida é feita mais feliz pelo afeto mútuo e a compreensão em nossa casa. $^{22}$ (CURIE, 1923, p. 89, tradução nossa)

Curie posiciona-se, quando questionada sobre a administração de carreira e vida privada, especialmente sobre ser mãe, e fala na sua autobiografia, em autossacrificio. A organizadora de sua turnê estadunidense, Missy Meloney, investiu no mito da mãe Marie Curie na mídia. Susan Quinn (1997) relata que, em

22 But of course the care of my children's education was only a part of my duties, my professional occupations taking most of my time. I have been frequently questioned, especially by women, how I could reconcile family life with a scientific career. Well, it has not been easy; it required a great deal of decision and of self-sacrifice. However, the family bond has been preserved between me and my now grown-up daughters, and life is made brighter by the mutual affection and understanding in our home. (CURIE, 1923, p. 89) um editorial da The Delineator dedicada a Marie, Missy a descrevia como uma mulher de rara beleza e "olhar de mãe", e desenhou para a mídia uma cientista que seria como uma mãe, a assistente de um povo angustiado na guerra. Curie era, ainda, uma mulher cientista, cuja carreira estava constituída num modelo masculino de ciência e de trabalho. Os compromissos de tempo integral para o trabalho, a cobrança pela produtividade, em pesquisa, as relações sociais para trabalhar em parceria e angariar recursos, a exibição pública, as relações academicamente competitivas e a valorização de características masculinas faziam parte do seu dia a dia (SILVA; RIBEIRO, 2014). Ainda assim, fica marcado em seu texto que as dificuldades só foram menores porque ela conseguiu ajuda do avô das meninas, que se juntou a elas, para encarar alguma rotina, após a morte da esposa. 0 fato de uma das suas filhas ter participado de seus trabalhos durante a Primeira Guerra, ter se tornado sua parceira científica e uma excelente cientista premiada engrandece a faceta maternal de seu mito.

\section{Os anos da guerra}

Em setembro de 1914, uma Marie devastada por um drama pessoal ${ }^{23}$ via seus colegas de universidade, laboratório e instituto, serem convocados para a guerra. A Alemanha declarava guerra à França e Marie ficou responsável por transportar, em segurança, uma amostra de rádio que encaminhou para a Universidade de Bordeaux. Como acontece de forma cíclica em tempos de guerra, os homens assumem a frente de batatha e as mulheres ocupam seus lugares. Num dos capítulos mais detalhados da autobiografia, Marie relata o período que passou servindo, escrevendo com um viés patriótico os esforços

23 Marie teve sua vida pessoal exposta na mídia e nos círculos acadêmicos e científicos por causa de seu envolvimento com um cientista chamado Paul Langevin. À época, Langevin era casado e seu relacionamento com Marie Curie quase a fez perder o segundo Nobel. 
que empreendeu para trabalhar de forma aplicada nos fronts. Ela explica como agiu:

O dever dominante imposto a cada um naquele momento foi ajudar o país, de alguma forma possivel, durante a crise extrema que enfrentava. Nenhum tipo de instruções para isto foi dada aos membros da Universidade. Coube a cada um tomar a sua própria iniciativa e meios de ação. Procurei, portanto, descobrir a maneira mais eficiente de fazer um trabalho útil, transformando meu conhecimento científico em algo produtivo. ${ }^{24}$ (CURIE, 1923, p. 94, tradução nossa)

A pesquisadora do rádio agora tinha a oportunidade de se tornar uma heroína de guerra e para isso recolheu equipamentos de raios $\mathrm{X}$ ociosos de laboratórios e os transformou em unidades móveis. As unidades, chamadas de Les petites Curie, eram levadas aos acampamentos por Marie e sua filha mais veIha que, depois de ingressar na Sorbonne, para estudar física e matemática, além de enfermagem, agora era sua colaboradora (GOLDSMI$\mathrm{TH}, 2006)$. Nessa seção sobre a guerra, Marie curiosamente fala de si, na primeira pessoa, deixando evidente que ela não só orquestrava as equipes como participava do transporte para o campo de batalha:

Foram instaladas cerca de duas centenas de estações radiológicas, que tiveram seus materiais melhorados por meio de meus esforços, na zona dos exércitos franceses e belgas, e nas regiões da França não ocupadas pelo exército. Além disso, eu equipei no meu laboratório e forneci para o exército vinte carros radiológicos. A estrutura destes carros foi doada por várias pessoas que desejavam ajudar; alguns deles ofereciam também o equipamento. Os carros eram de grande valia para o exército. ${ }^{25}$

24 The dominant duty imposed on every one at that time was to help the country in whatever way possible during the extreme crisis that it faced. No general instructions to this were given to the members of the University. It was left to each to take his own initiative and means of action. I therefore sought to discover the most efficient way to do useful work, turning my scientific knowledge to most profit. (CURIE, 1923, p. 94)

25 About two hundred radiologic installations were established or materially improved through my efforts
(CURIE, 1923, p. 95, tradução nossa)

Nos quatro anos de guerra, milhares de mulheres haviam trabalhado nas fábricas francesas, servindo em serviços de saúde, como enfermeiras e técnicas, e como administradoras de escolas, hospitais, fazendas e serviços de transportes. Quando a guerra acabou, essas mulheres se viram obrigadas a desocupar esses lugares, momentaneamente seus, e voltarem aos papéis tradicionais pré-guerra. 0 movimento pelos direitos das mulheres havia ganhado impulso, mas só mais de 20 anos depois as mulheres puderam se emancipar na França (GOLDSMITH, 2006). Contar-se como participante desse momento histórico parecia ser um orgulho para Marie Curie. Os soldados que morreriam sem cirurgia ou durante elas agora poderiam ter um diagnóstico de imagem que facilitava a vida dos cirurgiões do front. Sobre esses feridos, Curie fala com compaixão:

[...] nada era tão tocante quanto estar com os feridos e cuidar deles. Nós éramos atraídas por causa de seu sofrimento e pela paciência com que suportavam a dor. Quase todo mundo fazia o possivel para facilitar os exames de raio-x, mesmo com a dor causada pelos deslocamentos. Um aprendizado que tivemos logo foi conhecê-los individualmente e trocar com eles algumas palavras amigáveis. Aqueles que não eram familiarizados com o exame, queria muito ser tranquilizados sobre os efeitos do estranho aparelho que iriam experimentar. Eu nunca vou esquecer a terrivel impressão de toda essa destruição da vida humana e saúde. ${ }^{26}$ (CURIE, 1923, p. 97, tradução nossa)

in the zone of the French and Belgian armies, and in the regions of France not occupied by the army. I was able, besides, to equip in my laboratory and give to the army twenty radiologic cars. The frames of these cars were donated by various persons who wished to be helpful; some of them offered also the equipment. The cars were of the greatest service to the army. (CURIE, 1923, p. 95)

26 [...] but nothing was so moving as to be with the wounded and to take care of them. We were drawn to them because of their suffering and because of the patience with which they bore it. Almost everyone did his best to facilitate the X-ray examination, notwithstanding the pain caused by any displacement. One learned very soon to know them individually and to 
Mas para atender a uma quantidade maior de feridos, Marie necessitava de uma equipe técnica móvel e foi chamada pelo exército para ministrar um curso para técnicos. A precariedade dos locais de treinamento e a ausência de equipamentos fez Marie mudar de ideia e pensar em treinar enfermeiras. A escola de manipulatrices, como eram chamadas, formou centenas de moças que eram enviadas para os postos de radiologia espalhados pelo país. As moças não tinham formação científica, variavam de empregadas domésticas a mulheres ricas da sociedade, estavam aprendendo de Marie os conceitos fisicos para operar equipamentos de raios $\mathrm{X}$. Em um comentário sobre o cumprimento desta tarefa, Curie afirmou que esta era uma tarefa que as mulheres podiam fazer bem tanto na paz quanto na guerra. Trabalhos de mulher, mas para qualquer tempo (QUINN, 1997).

Com o término na guerra, a França começa a organizar-se, inclusive o Instituto do Rádio, e, em suas Notas autobiográficas, Marie escreve mais explicitamente sobre a campanha de arrecadações:

O trabalho do laboratório foi reorganizado, com o retorno do pessoal e dos alunos. Mas, pelas circunstâncias restritas sob as quais o país está vivendo, o laboratório não tinha meios para continuar seu desenvolvimento. Particularmente é necessário um hospital independente para radioterapia (que é chamado curieterapia, na França) e uma estação experimental, fora de Paris, para experiências com grandes quantidades de material, que são necessários para o progresso do nosso conhecimento de elementos radioativos. Eu mesma já não sou jovem, e frequentemente me pergunto se, apesar dos recentes esforços do governo e auxiliado por algumas doações privadas, haverá uma sucessão garantida para aqueles que virão depois de

exchange with them a few friendly words. Those who were not familiar with the examination, wanted very much to be reassured about the effect of the strange apparatus they were going to experience. I can never forget the terrible impression of all that destruction of human life and health. (CURIE, 1923, p. 97) mim, no Instituto de Rádio, à memória de Pierre Curie e o interesse maior da humanidade. No entanto, um precioso incentivo aconteceu no ano de 1921. Por iniciativa de uma generosa filha dos Estados Unidos, Sra. W. B. Meloney, as mulheres desse grande país recolheram um fundo, o "Marie Curie Radium Fund", e ofereceram como presente um grama de rádio para ser colocado inteiramente à minha disposição para investigação científica. ${ }^{27}$ (CURIE, 1923, p. 100, tradução nossa)

Por causa de seus serviços durante a guerra, Marie ficou conhecida por conseguir elaborar e aplicar suas pesquisas, especialmente às áreas médicas e biológicas. Mas se acredita que houve uma confusão entre o trabalho desenvolvido em seu laboratório, radioatividade, e aquele feito nas fronteiras de guerra, com equipamentos de raios $X$. A partir disso, a mídia passou a divulgar que Marie Curie poderia encontrar uma cura para o câncer. À época, um editorial da The Delineator afirmava: "dizem que Madame Curie, se the derem um único grama de rádio, pode fazer avançar a ciência até o ponto em que, em medida muito grande, o câncer poderá ser eliminado" (QUINN, 1997). Marie, segundo Susan Quinn (1997), sempre propagou que as contribuições da pesquisa

27 The work of the laboratory has been reorganized, with the return of the mobilized personnel and the students. But in the restrained circumstances under which the country still exists, the laboratory lacks ways and means for its efficient development. Particularly are wanted an independent hospital for radiumtherapy (which is called Curietherapy in France), and an experimental station, outside of Paris, for experiments on great quantities of material, such as are needed for the progress of our knowledge of radioactive elements. I myself am no longer young, and I frequently ask myself whether, in spite of recent efforts of the government aided by some private donations, I shall ever succeed in building up for those who will come after me an Institute of Radium, such as I wish to the memory of Pierre Curie and to the highest interest of humanity. However, a precious encouragement came to me in the year 1921. On the initiative of a generous daughter of the United States, Mrs. W. B. Meloney, the women of that great American country collected a fund, the "Marie Curie Radium Fund", and offered me the gift of a gramme of radium to be placed entirely at my disposal for scientific research. (CURIE, 1923, p. 100) 
com o rádio para a luta contra o câncer eram indiretas e que o rádio que receberia dos Estados Unidos serviria para substituir o rádio que ela isolara anos antes. Essa exaltação de sua figura como salvadora seria resultado de um momento histórico, em que se multiplicavam propostas de aplicação para os fenômenos rádio-atômicos, e se divulgavam a figura de cientistas como proponentes dessas ações, ainda que se pertencesse a um grupo de pesquisa multifacetado.

A reverberação do mito da mulher que pode salvar milhares de vidas não consta na biografia de Curie, é desonesto, fruto da mídia da época e nos faz pensar mais uma vez sobre o caráter binário das ciências. 0 mito Curie produzido a partir das narrativas polifônicas sobre sua vida era o de uma mulher que, até poderia ser um gênio das ciências, ter elaborado um arcabouço teórico para explicar a constituição da matéria, ter aparecido ao lado de grandes homens celebrados como eminentes físicos teóricos como Einstein e Rutherford, mas que era divulgada, nos Estados Unidos, para o mundo e talvez até hoje, como uma estudiosa que poderia aplicar seu trabalho a uma finalidade da área de saúde. Mulheres não poderiam ser "naturalmente" cientistas porque seu caráter de objetividade nunca seria alcançado por pessoas do sexo feminino. Sua carga emocional, estrutura biológica e a centralidade da esfera doméstica seriam discursos utilizados como justificativa para esse afastamento. Circulava um discurso sobre Curie no laboratório e na enfermaria, de uma ciência abstrata, mas também aplicada às causas humanitárias. Em contrapartida, muitas mulheres eram consideradas curadoras e cuidadoras, principalmente de crianças, outras mulheres e idosos. Era seu papel natural. Era fácil pensar que as mulheres envolvidas com atividades ligadas ao cuidado, mesmo na esfera profissional, não pareciam ter transgredido seus papéis domésticos (DES
JARDINS, 2011). Não poderiam ser comparadas àqueles que ocupavam o espaço estéril do laboratório.

\section{Considerações finais}

Se a ciência é uma invenção, ${ }^{28}$ uma cientista também o é. Numa segunda viagem para os Estados Unidos, dessa vez para receber mais um grama de rádio para o Instituto do Rádio da Varsóvia, ela ouve o seguinte discurso do físico George Pegram: "Nós, como o resto do mundo queremos honrar Mme. Curie pela sua vida, pela devoção inabalável à ciência, seu serviço patriótico, sua modéstia. Queremos honrá-la como esposa e mãe. A nobreza de sua vida é tanta que a nossa admiração por seu caráter quase desvia nossa atenção de seu ser científico" (DES JARDIN, 2010). A ciência de Curie foi completamente apagada. Barbara Goldsmith (2006) reitera que Marie Curie empreendeu esforços para desfazer o mito criado a partir de sua vida. Pediu retratações da imprensa americana que a proclamavam a santa da ciência, Mãe do Ano ou a resposta para a cura do câncer. Parecia ser tarde, seu altruísmo lendário já tinha sido estabelecido e fixado no imaginário popular.

Não existe uma Curie verdadeira, e ela, como qualquer mulher, estava atolada em uma complexidade muito semelhante ao seu legado histórico. É só a partir do entendimento dessa complexidade que podemos reinscrevê-la de novo e de novo no século XXI. Olhar para a sua autobiografia e entender a polifonia da sua construção, sinaliza que as questões que dizem respeito ao gênero, em sua articulação com a ciência, estão completamente enraizadas na cultura. É mais do que necessário criar e recriar Curie, porque sua vida reverbera nas mulheres cientistas em geral, para subverter os discursos que as mu-

28 Ver Paula Henning (2012). 
Iheres da ciência devem recusar sua linha de subjetividade feminina. É necessário reescre- ver e reinscrever as mulheres na história das ciências e na atualidade.

\section{Referências}

ABRAHÃO, Maria Helena Menna Barreto. A aventura (auto)biográfica: teoria e empiria. Porto Alegre: EDIPUCRS, 2004.

COSTA, Luciano Bedin da. Biografema como estratégia biográfica: escrever uma vida com Nietzsche, Deleuze, Barthes e Henry Miller. 2010. 180 p. Tese (Doutorado em Educação) - Programa de Pós-Graduação em Educação, Universidade Federal do Rio Grande do Sul, Porto Alegre, 2010.

CURIE, Marie. Autobiographical notes. In:

Pierre Curie. New York: Macmillian Company, 1923. p. 68-108.

DES JARDINS, Julie. American memories of Madame Curie: prisms on the gendered culture of science. In: CHIU, Mei-Hung; GILMER, Penny; TREAGUST, David. (Orgs.). Treagust Celebrating the 100th Anniversary of Madame Marie Sklodowska Curie's Nobel Prize in Chemistry. New York: SensePublishers, 2011. p. 59-85.

DES JARDIN, Julie. The Madame Curie complex: the hidden history of women in science. New York: Feminist Press, 2010

FISCHER, Beatriz Daudt. Foucault e histórias de vida: aproximações e que tais... In: ABRAHÃO, Maria Helena Menna Barreto. (Org.). A aventura (auto)biográfica: teoria e empiria. Porto Alegre: EDIPUCRS, 2004. p. 143-161.

FORTUNATI, Vita. Mirror shards: conflicting images between Marie Curie's autobiography and her biographies. In: GOVONI, Paola; FRANCESCHI, Zelda Alice (Eds.). Writing about lives in science: (auto) biography, gender, and genre. Göttingen, Alemanha: V\&R Unipress, 2014. p. 141-160.

GOBBI, Maria Cristina. Método biográfico. In: DUARTE, Jorge; BARROS, Antonio. (Orgs.). Métodos e técnicas de pesquisa em comunicação. São Paulo: Atlas, 2005. p. 84-97.
GOLDSMITH, Barbara. Gênio obsessivo: o mundo de Marie Curie. São Paulo: Companhia das Letras, 2006.

HALL, Linley Erin. Who's afraid of Marie Curie?: the challenges facing women in science and technology. California: Seal Press: 2007.

HENNING, Paula. Resistência e criação de uma gaia ciência em tempos líquidos. Ciência \& Educação, v. 18, n. 2, p. 487-502, 2012.

KELLER, Evelyn Fox. Feminism and science. Signs, v. 7, n. 3, p. 589-602, 1982.

KELLER, Evelyn Fox. Gender and Science: an update. In: WYER, Mary et al. Women, science and technology: a reader in feminist science studies. London: Routledge, 2001. p. 128-137.

KELLER, Evelyn Fox. Gender and science: origin, history and politics. Osiris, v. 10, p. 26-38, 1995.

KELLER, Evelyn Fox. Qual foi o impacto do feminismo na ciência? Cadernos Pagu, n. 27, p. 13-34, 2006.

KOHLSTEDT, Sally Gregory; LONGINO, Helen. The women, gender, and science question: what do research on women in science and research on gender and science have to do with each other? Osiris, v. 12, p. 3-15, 1997.

LIMA, Betina S. Teto de vidro ou labirinto de cristal? As margens femininas das ciências. 2008. 133f. Dissertação (Mestrado em História) - Programa de Pós-Graduação em História, Universidade de Brasília, Brasília, 2008.

MELONEY, Marie "Missy". Introduction. In: CURIE, Marie. Pierre Curie. New York: Macmillian Company, 1923. p. 11-16.

PUGLIESE, Gabriel. Um sobrevôo no "Caso Marie Curie": um experimento de antropologia, gênero e ciência. Revista de Antropologia, v. 50, n. 1, p. 347385, 2007. 
QUINN, Susan. Marie Curie: uma vida. São Paulo: Scipione, 1997.

REVEL, Judith. Uma subjetividade que jamais cessa de inventar-se a si própria. Revista do Instituto Humanitas Unisinos, n. 203, p. 20-31, 2006. Disponível em: <http://www.ihuonline.unisinos.br>. Acesso em: 28 ago. 2016.

ROHDEN, F. A construção da diferença sexual na medicina. Cadernos de Saúde Pública, n. 19, v. 2, p. 201-212, 2003.

SCHIEBINGER, L. Skeletons in the closet: the first illustrations of the female skeleton. Berkeley: University of California Press, 1987.

SCHIEBINGER, Londa. 0 feminismo mudou a ciência? São Paulo: EDUSC, 2001.

SCHWARTZ, Juliana; CASAGRANDE, Lindamir Salete; LESZCZYNSKI, Sonia Ana Charchut; CARVALHO, Marilia Gomes de. Mulheres na informática: quais foram as pioneiras? Cadernos Pagu, n. 27, p. 255-278, 2006.

SEDEÑO, Eulalia Pérez. Ciência, valores e guerra na perspectiva CTS. In: ALFONSO-GOLDFARB, Ana Maria;
BELTRAN, Maria Helena Roxo. (Orgs.). Escrevendo a história da ciência: tendências, propostas e discussões historiográficas. São Paulo: Livraria da Física; Educ; Fapesp, 2004. p. 201-229.

SILVA, Fabiane Ferreira; RIBEIRO, Paula Regina Costa. Trajetórias de mulheres na ciência: "ser cientista" e "ser mulher". Ciência \& Educação, n. 2, v. 20, p. 449-466, 2014.

TOSI, Lucía. Mulher e ciência: a revolução científica, a caça às bruxas e a ciência moderna. Cadernos Pagu, v. 10, p. 369-397, 1998.

VIART, Dominique, Dime quién te obsesiona: paradojas de lo autobiográfico. Cuadernos hispanoamericanos, n. 621, p. 63-74, 2002.

WIRTÉN, Eva Hemmungs. Making Marie Curie: intellectual property and celebrity culture in an age of information. Chicago: The University of Chicago Press, 2015.

Recebido em: 04.10.2016

Aprovado em: 16.11..2016

Paloma Nascimento dos Santos é doutoranda em Educação em Ciências, PPGQVS-UFRGS, Universidade Federal do Rio Grande do Sul, pesquisadora do Núcleo de Estudos em Currículo e Saberes - NECS/UFRGS. e-mail: pns.paloma@gmail.com Rua dos Andradas, 793, ap. 34, Centro Histórico, Porto Alegre, RS CEP: 90020-003

Rochele de Quadros Loguercio é Doutora em Ciências Biológicas (Bioquímica) - UFRGS. Professora da Universidade Federal do Rio Grande do Sul. Núcleo de Estudos em Currículo e Saberes - NECS/UFRGS. e-mail: rochelel@gmail.com Programa de Pós-Graduação em Educação em Ciências, Rua Ramiro Barcelos, 2600 (Prédio Anexo), Porto Alegre, RS, CEP: 90035-003 